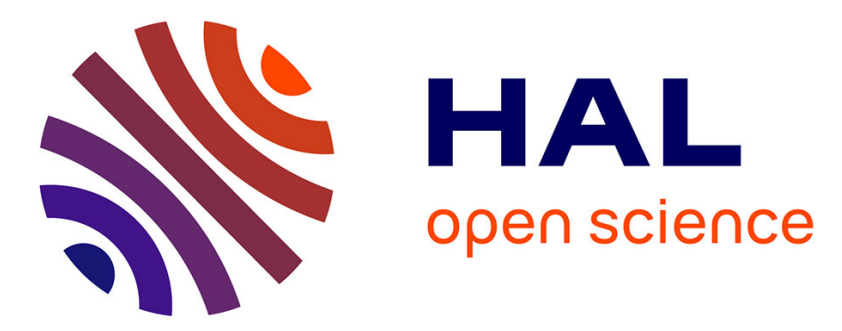

\title{
Low barrier methyl rotation in 3-pentyn-1-ol as observed by microwave spectroscopy
}

\author{
Konrad Eibl, Raphaela Kannengiesser, Wolfgang Stahl, Ha Vinh Lam
}

Nguyen, Isabelle Kleiner

\section{- To cite this version:}

Konrad Eibl, Raphaela Kannengiesser, Wolfgang Stahl, Ha Vinh Lam Nguyen, Isabelle Kleiner. Low barrier methyl rotation in 3-pentyn-1-ol as observed by microwave spectroscopy. Molecular Physics, 2016, 114 (23), pp.3483-3489. 10.1080/00268976.2016.1239034 . hal-03183104

\author{
HAL Id: hal-03183104 \\ https://hal.science/hal-03183104
}

Submitted on 26 Mar 2021

HAL is a multi-disciplinary open access archive for the deposit and dissemination of scientific research documents, whether they are published or not. The documents may come from teaching and research institutions in France or abroad, or from public or private research centers.
L'archive ouverte pluridisciplinaire $\mathbf{H A L}$, est destinée au dépôt et à la diffusion de documents scientifiques de niveau recherche, publiés ou non, émanant des établissements d'enseignement et de recherche français ou étrangers, des laboratoires publics ou privés. 


\title{
PAPER
}

\section{Low barrier methyl rotation in 3-pentyn-1-ol as observed by microwave spectroscopy}

\author{
Konrad Eibl ${ }^{a, b}$, Raphaela Kannengießer ${ }^{a}$, Wolfgang Stahl ${ }^{a}$, Ha Vinh Lam Nguyen ${ }^{b *}$, \\ Isabelle Kleiner ${ }^{b}$ \\ ${ }^{a}$ Institute of Physical Chemistry, RWTH Aachen University, Landoltweg 2, D-52074 \\ Aachen, Germany; ${ }^{b}$ Laboratoire Interuniversitaire des Systèmes Atmosphériques (LISA), \\ CNRS UMR 7583, Université Paris-Est Créteil and Université Paris Diderot, 61 avenue \\ du Général de Gaulle, F-94010 Créteil cedex, France. \\ (Received 00 Month 200x; final version received 00 Month 200x)
}

\begin{abstract}
The rotational spectrum of 3-pentyn-1-ol, $\mathrm{CH}_{3}-\mathrm{C} \equiv \mathrm{C}-\mathrm{CH}_{2} \mathrm{CH}_{2} \mathrm{OH}$, was measured using a molecular beam Fourier transform microwave spectrometer operating in the frequency range from 2 to $26.5 \mathrm{GHz}$. A two-dimensional potential energy surface was calculated at the MP2/6$311++\mathrm{G}(\mathrm{d}, \mathrm{p})$ level of theory for a conformational analysis, yielding five conformers. The most stable conformer exhibits $\mathrm{C}_{1}$ symmetry and was assigned in the spectrum by comparison with the results from quantum chemical calculations. The barrier to internal rotation of the propynyl methyl group $\mathbf{C H}_{3}-\mathrm{C} \equiv \mathrm{C}-$ was found to be only $9.4552(94) \mathrm{cm}^{-1}$. Molecular parameters and internal rotation parameters could be accurately determined using the program XIAM and BELGI- $_{1}$. The internal rotation barrier was compared with those of other molecules containing a propynyl methyl group.
\end{abstract}

Keywords: propynyl, rotational spectroscopy, internal rotation, large amplitude motion, conformation analysis, potential energy surface

\section{Introduction}

The internal rotation of methyl groups has been studied by microwave spectroscopy since this technique was established more than 60 years ago. Many torsional barriers were accurately determined, but only in very few molecules the barriers are very low (say $V_{3}<30 \mathrm{~cm}^{-1}$ ). The classical example is acetamide, where a threefold barrier to internal rotation of $25 \mathrm{~cm}^{-1}$ was observed [1]. Surprisingly, this situation did not change much in the modern ages of computational chemistry. There are several reasons for this, e.g.: (i) Low barriers are hard to calculate; (ii) rotational spectra of molecules with low barriers to internal rotation are hard to assign and to fit; and (iii) no simple intuitive rules exist to predict the barrier height. (iv) In some cases like m-fluorotoluene [2] or trans-methyl nitrite [3], the threefold- and sixfold-symmetrical potential components become comparable in magnitude which complicates the analysis of the spectrum.

It is known that the barrier to internal rotation of the methyl groups in ethane is about $1000 \mathrm{~cm}^{-1}$ [4]. If a C-C-triple bond is inserted between the methyl groups as a spacer, which is the case in dimethylacetylene (2-butyne), $\mathrm{CH}_{3}-\mathrm{C} \equiv \mathrm{C}-\mathrm{CH}_{3}$, the molecule is assumed to exhibit almost free internal rotation [5]. Unfortunately, it

*Corresponding author. Email: lam.nguyen@lisa.u-pec.fr 
is not possible to study dimethylacetylene by microwave spectroscopy because this molecule does not have a permanent dipole moment. However, according to the basic concepts of this chemical bonding, a methyl group attached to a non-linear acetylene fragment $\mathbf{C H}_{\mathbf{3}}-\mathrm{C} \equiv \mathrm{C}-\mathrm{R}$ (called the propynyl methyl group) should experience essentially free internal rotation, i.e. the barrier height is extremely low $\left(V_{3}<10 \mathrm{~cm}^{-1}\right)$. This was confirmed by two molecules related to dimethylacetylene, dimethylacetylene- $d_{3}[6], \mathrm{CH}_{3}-\mathrm{C} \equiv \mathrm{C}-\mathrm{CD}_{3}$, and methylsilylacetylene [7], $\mathrm{CH}_{3}-\mathrm{C} \equiv \mathrm{C}-\mathrm{SiH}_{3}$, which possess methyl torsional barriers of $5.62(16) \mathrm{cm}^{-1}$ and $3.77(70) \mathrm{cm}^{-1}$, respectively. An even lower $V_{3}$ potential of $2.20(12) \mathrm{cm}^{-1}$ as well as $1.00900(42) \mathrm{cm}^{-1}$ was observed for tetrolyl fluoride $(\mathbf{R}=\mathrm{COF})[8]$ and 2-butynoic acid $(\mathbf{R}=\mathrm{COOH})[9]$, respectively.

The barrier to internal rotation of the propynyl methyl group rises slightly to $6.93(9) \mathrm{cm}^{-1}$ in 2-butynol $\left(\mathbf{R}=\mathrm{CH}_{2} \mathrm{OH}\right)$ [10]. In the study on 1-chloro-2butyne [11] $\left(\mathbf{R}=\mathrm{CH}_{2} \mathrm{Cl}\right)$, Stolwijk and van Eijck reported a potential barrier height of 10.05(9) $\mathrm{cm}^{-1}$, which is the largest value found for this group of molecules up to now.

In short, microwave spectroscopic investigations on several molecules of the structure $\mathbf{C H}_{\mathbf{3}}-\mathrm{C} \equiv \mathrm{C}-\mathbf{R}$ have confirmed that the threefold barrier to internal rotation of the propynyl methyl group is low, varying in a wide range from about $1 \mathrm{~cm}^{-1}$ to $10 \mathrm{~cm}^{-1}$. Currently, no rules exist to explain this observation.

This induced us to measure the microwave spectrum of 3-pentyn-1-ol ( $\mathbf{R}=$ $\left.\mathrm{CH}_{2} \mathrm{CH}_{2} \mathrm{OH}\right)$ to find out if the length of the alkyl chain affects the barrier height of the propynyl methyl group. The experimental work is supplemented by quantum chemical calculations. Additionally, we determined the molecular structure of the most stable conformer of 3-pentyn-1-ol by comparing the observed rotational constants and the orientation of the propynyl methyl group in the principal axis system with the calculated values. This structure will be compared to that of the closely related molecule 3-butyn-1-ol, $\mathrm{H}-\mathrm{C} \equiv \mathrm{C}-\mathrm{CH}_{2} \mathrm{CH}_{2} \mathrm{OH}$ [12].

\section{Theoretical}

\subsection{Quantum chemical calculations}

Since the rotation of the methyl group does not create new conformations, the conformational landscape of 3-pentyn-1-ol is completely defined by two dihedral angles $\varphi_{1}=\measuredangle\left(C_{6}, C_{7}, C_{10}, O_{13}\right)$ and $\varphi_{2}=\measuredangle\left(C_{7}, C_{10}, O_{13}, H_{14}\right)$ (for atom labeling see Fig. 1), corresponding to the rotations about the $\mathrm{C}_{7}-\mathrm{C}_{10}$ and $\mathrm{C}_{10}-\mathrm{O}_{13}$ bonds. To obtain stable conformers, we calculated a potential energy surface (PES) depending on $\varphi_{1}$ and $\varphi_{2}$ (Fig. 2). These angles were varied in a grid of $10^{\circ}$, and the starting geometries were optimized at the MP2/6-311++G(d,p) level of theory using the program Gaussian [13]. Due to the linearity of the $\mathrm{CH}_{3}-\mathrm{C} \equiv \mathrm{C}-\mathrm{CH}_{2}$ part, the geometries represented by $\left(\varphi_{1}, \varphi_{2}\right)$ and $\left(-\varphi_{1},-\varphi_{2}\right)$ have the same potential energy. Therefore only half of the full PES calculations are needed.

We parameterized the calculated energies using a two-dimensional Fourier expansion based on terms with the correct symmetry of the angles $\boldsymbol{\varphi}_{\mathbf{1}}$ and $\boldsymbol{\varphi}_{\mathbf{2}}$. The corresponding coefficients are available in Tab. S-1 in the Supporting Information. The PES was drawn as a contour plot using the value in degrees of the two dihedral angles versus the relative energies calculated from these coefficients and is illustrated in Fig. 2.

Five conformers within an energy range of $9 \mathrm{~kJ} \cdot \mathrm{mol}^{-1}$ were obtained and subsequently re-optimized under full geometry relaxation. Frequency calculations confirm that they are true minima rather than saddle points. The energetically most 

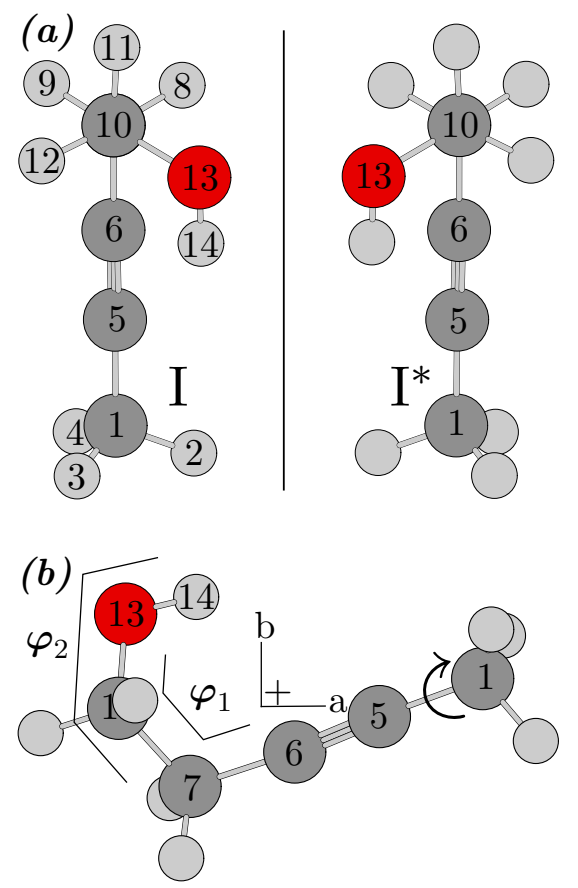

Figure 1. (a) The energetically most favorable conformer of 3-pentyn-1-ol (conformer $\mathbf{I}$ ) and its enantiomer $\left(\mathbf{I}^{*}\right)$. (b) View of conformer $\mathbf{I}$ onto the $a b$-plane in the principal axis system.

favorable conformer (called conformer $\mathbf{I}$ ) is depicted in Fig. 1; other conformers are shown in Fig. 3. Their rotational constants, energies relative to that of conformer $\mathbf{I}$, and dipole moment components are summarized in Tab. 1 . In all conformers, $\boldsymbol{\varphi}_{\mathbf{1}}$ is approximately $\pm 60^{\circ}$, or $180^{\circ}$, corresponding to a staggered arrangement of the $\mathrm{OH}$ group. Only conformer II has $\mathrm{C}_{s}$ symmetry; all other conformers exist as a pair of enantiomers. The Cartesian coordinates are given in Tab. S-2.

The zero point corrected energies of conformers II to $\mathbf{V}$ are about $4-9 \mathrm{~kJ} \cdot \mathrm{mol}^{-1}$ higher than that of conformer I. Because of the very low rotational temperature of about $2 \mathrm{~K}$ in the molecular beam, they are probably "frozen out" and do not appear in the spectrum. We thus only focus on conformer $\mathbf{I}$ in our experiments. The dipole moment components in $a, b$, and $c$ direction of this conformer are sufficiently large. Therefore $a, b$, and $c$ type transitions are expected to be present in the spectrum.

Additionally, the geometry of conformer I optimized at the MP2/6-311++G(d,p) level of theory was re-optimized with different methods and basis sets to compare the calculated rotational constants with the experimental values and to check for convergence. The results are listed in Tab. S-3.

The propynyl methyl group in 3-pentyn-1-ol undergoes internal rotation. As a consequence, all lines in the microwave spectrum split into an $\mathrm{A}$ and an $\mathrm{E}$ component [14]. We calculated the barrier to internal rotation, also at the MP2/6$311++\mathrm{G}(\mathrm{d}, \mathrm{p})$ level of theory, by varying the dihedral angle $\varphi_{3}=\measuredangle\left(C_{10}, C_{7}, C_{1}, H_{2}\right)$ in a grid of $10^{\circ}$, while all other parameters were optimized. Only a rotation from $0^{\circ}$ to $120^{\circ}$ has to be considered because of the threefold permutation of the methyl group. The same calculations were carried out for other combinations of methods and basis sets. The results are also summarized in Tab. S-3. 


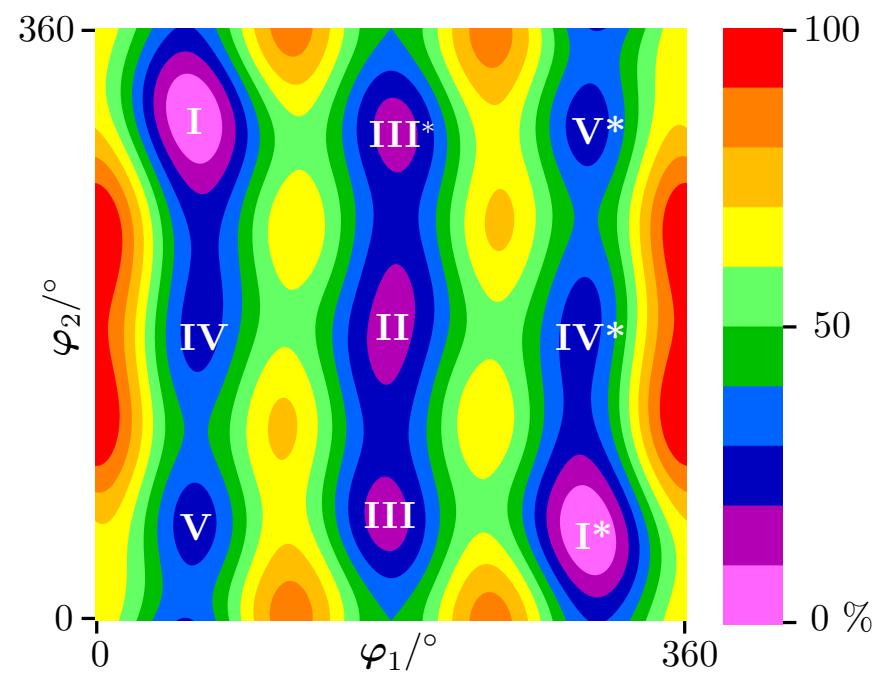

Figure 2. The potential energy surface of 3-pentyn-1-ol calculated at the MP2/6-311++G(d,p) level of theory depending on the dihedral angles $\varphi_{1}=\measuredangle\left(C_{6}, C_{7}, C_{10}, O_{13}\right)$ and $\varphi_{2}=$ $\measuredangle\left(C_{7}, C_{10}, O_{13}, H_{14}\right)$. The color code indicates the energy (in percent) relative to the energy minimum $\mathrm{E}_{\min }=-269.791196 \mathrm{E}_{h}$ $(0 \%)$. The energy maximum $(100 \%)$ is $\mathrm{E}_{\max }=39.2 \mathrm{~kJ} \cdot \mathrm{mol}^{-1}$.

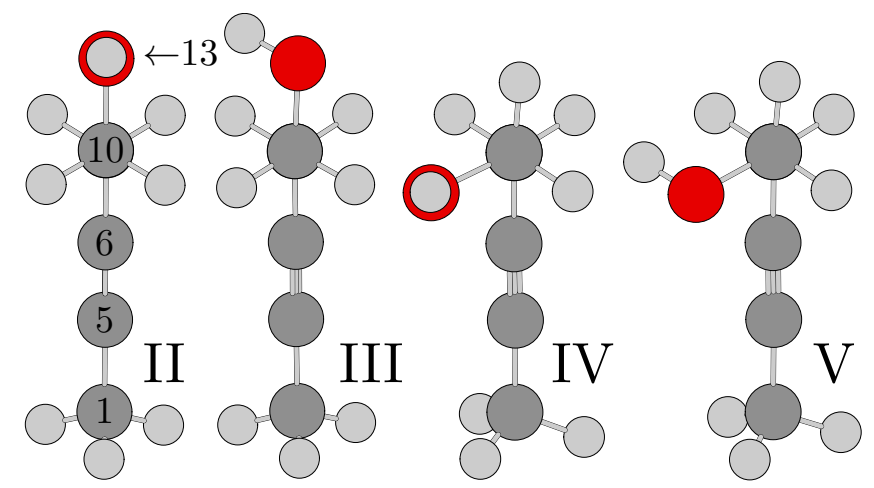

Figure 3. Structures of conformers II to $\mathbf{V}$ of 3-pentyn-1-ol.

Table 1. The energies relative to the lowest energy conformer I with its absolute energy of $\mathrm{E}=-269.791196 \mathrm{E}_{h}\left(\mathrm{in} \mathrm{kJ} \cdot \mathrm{mol}^{-1}\right)$, zero point corrected energies relative to that of conformer $\mathbf{I}\left(\triangle \mathrm{E}_{Z P E}\right.$ in $\left.\mathrm{kJ} \cdot \mathrm{mol}^{-1}\right)$, rotational constants (in $\left.\mathrm{GHz}\right)$, and dipole moment components (in Debye based on the nuclear coordinates given in Tab. S-2) of the five conformers of 3-pentyn-1-ol calculated at the MP2/6-311++G(d,p) level of theory.

\begin{tabular}{lrrrrrrrr}
\hline & $\triangle \mathrm{E}$ & $\triangle \mathrm{E}_{\mathrm{ZPE}}$ & $A$ & $B$ & $C$ & $\mu_{a}$ & $\mu_{b}$ & $\mu_{c}$ \\
\hline I & 0 & 0 & 8.0269 & 1.6892 & 1.4718 & 1.774 & -1.059 & 0.710 \\
II & 6.57 & 3.98 & 19.1378 & 1.2092 & 1.1622 & 0.757 & -1.835 & 0.000 \\
III & 6.34 & 5.67 & 18.4968 & 1.2065 & 1.1604 & -1.524 & 0.384 & 1.307 \\
IV & 10.11 & 8.58 & 8.5047 & 1.5960 & 1.4203 & -1.031 & -0.306 & 1.444 \\
V & 9.83 & 9.07 & 8.2789 & 1.5969 & 1.4174 & -0.096 & -1.527 & -0.732 \\
\hline
\end{tabular}

\subsection{Effective Hamiltonian methods}

As we shall see in the experimental part, the spectrum of 3-pentyn-1-ol is analyzed using two different programs treating internal rotation, the XIAM [15] and the BELGI-C $_{1}$ code [16]. Both programs can be accessed at the PROSPE website [17].

The program XIAM uses the combined axis method, which is a combination of the principal axis method and the rho axis method. The Hamilton matrix of each internal rotor is set up in its own rho axis system. After diagonalization, the eigenvalues and torsional integrals are used to set up the Hamilton matrix in the principal axis 
system. Matrix elements of each internal rotor are added to the Hamilton matrix, which also contains the matrix elements of the overall rotation. Finally, the matrix is diagonalized to obtain the rotorsional eigenvalues.

The program BELGI- $\mathrm{C}_{1}$ uses a two-step diagonalization procedure as well where both steps are carried out in the rho axis system. In the first step the torsional Hamiltonian $H_{T}=F\left(\mathbf{p}_{\alpha}-\rho \mathbf{P}_{a}\right)^{2}+V(\alpha)$ is diagonalized in the basis set $\exp (i[3 k+$ $\sigma] \alpha)|K\rangle$ [18], where $k$ is an integer in the range $-10 \leq k \leq 10,|K\rangle$ is the symmetric top eigenfunction, and $\sigma$ is either 0 for the A states or \pm 1 for the E states. $V(\alpha)$ is the internal rotation potential function, $F$ is the internal rotation constant, $\mathbf{p}_{\alpha}$ is the internal rotation angular momentum conjugate to the torsional angle $\alpha, \mathbf{P}_{a}$ is the $a$ component of the total rotational angular momentum, and $\rho$ is the coupling constant between the internal rotation and the global rotation. In the first step, a $(2 k+1) \times(2 k+1)=21 \times 21$ Hamiltonian matrix is diagonalized for each $K$ value and the torsional eigenvalues and eigenvectors are obtained. In the second step, we used a basis set consisting of products of the torsional eigenfunctions obtained from the first step diagonalization and the symmetric top wavefunctions $|J K\rangle$ to diagonalize the rest of the terms of the Hamiltonian, i.e. $H_{R}, H_{c d}$, and $H_{\text {int }}$ allowed for the $\mathrm{C}_{1}$ symmetry [16]. The nine lowest torsional states $v_{t}$ are taken to create a matrix of the size $(2 J+1) \cdot 9 \times(2 J+1) \cdot 9$ associated with the second step. This truncation has been tested so that it does not affect the energy calculation of the ground torsional state $v_{t}$.

For comparable results, the same $k_{\max }=10$ is used in the program XIAM. Unlike BELGI, XIAM normally uses only the lowest torsional state, leading to a $(2 J+1) \times$ $(2 J+1)$ matrix, which significantly increases the speed of the calculation. The program BELGI- $\mathrm{C}_{1}$ is referred to as a global approach [19], because it takes into account explicitly the interaction between the nine lowest torsional states, unlike the XIAM code which fits each $v_{t}$ state separately. Additionally, compared to the XIAM code, a number of higher order terms can be fitted in the BELGI-C $\mathrm{C}_{1}$ code. It has been shown in a number of studies that the XIAM code and the BELGI codes are complementary $[20,21]$. The XIAM code is widely used for many internal rotor problems mainly because of its ease of use and speed. However, in cases with rather low barriers, E species transitions are not always satisfactorily predicted due to the fact that the interactions between torsional states can be large. An example is allyl acetate $\left(V_{3}=98.1 \mathrm{~cm}^{-1}\right)$. For this molecule the A species could be fitted with a standard deviation of $2.7 \mathrm{kHz}$ within the measurement accuracy of $3 \mathrm{kHz}$, but for the $\mathrm{E}$ species a standard deviation of $54.0 \mathrm{kHz}$ was obtained with XIAM [22]. Using the BELGI- $\mathrm{C}_{1}$ code, both species were fitted to a rms deviation of $2.1 \mathrm{kHz}$.

\section{Experimental}

\subsection{Measurements}

The sample of 3-pentyn-1-ol (98\%) was purchased from Alfa Aesar (Karlsruhe, Germany) and used without further purification. The rotational spectrum was measured in the $2-26.5 \mathrm{GHz}$ frequency range using a molecular beam Fourier transform microwave spectrometer described in Ref. 23. A helium stream at a pressure of approximately $150-200 \mathrm{kPa}$ was flown over the sample and the helium - 3-pentyn-1-ol mixture was expanded into the cavity as a pulsed molecular jet.

A broadband scan in the frequency range from 11 to $17 \mathrm{GHz}$ was recorded as overlapping spectra with a step size of $0.25 \mathrm{MHz}$ where only approximate line positions are indicated. Afterwards, all lines were remeasured at higher resolution. 
Each of them appeared as a doublet due to the Doppler effect arising from the molecular beam expansion in the coaxial arrangement of the supersonic jet and resonator axes. For most transitions, we found a line width in the range from 10 to $25 \mathrm{kHz}$. This enabled us to determine transition frequencies with a measurement accuracy of approximately $2 \mathrm{kHz}$.

\subsection{Spectral analysis and fits}

As mentioned in section 2.1, we only attempted to assign the spectrum of conformer $\mathbf{I}$. At the beginning, we neglected internal rotation and treated 3-pentyn1-ol as an effective rigid rotor, i.e. only the A species lines were considered. Using the rotational constants calculated at the MP2/6-311++G(d,p) level of theory, we predicted a theoretical spectrum in the same frequency range as that of the broadband scan. Seven lines belonging to the $a$-type $R$ branch with $J=4 \leftarrow 3$ and $K_{a} \leq 3$ were first assigned and fitted with the program XIAM, yielding accurate $B$ and $C$ rotational constants. In agreement with the largest calculated dipole moment component in $a$ direction, these lines were the most intense in the spectrum. Thereafter, some $b$-type $Q$ branch transitions were also assigned which fixed the $A$ rotational constant. A total of 52 A species lines could be fitted using only the rotational constants and quartic centrifugal distortion constants to a root-meansquare (rms) deviation of $2.1 \mathrm{kHz}$, which is almost the measurement accuracy. The fitted parameters are given as Fit A in Tab. 2. A list of all measured lines is available in Tab. S-4.

As a next step, we took the methyl internal rotation into account and predicted the $\mathrm{E}$ species frequencies with the program XIAM. The initial barrier was assumed to be $7 \mathrm{~cm}^{-1}$, which is the value calculated at the MP2/6-311++G(d,p) level of theory (see section 2.1). The angles between the internal rotor axis and the principal axes of inertia were also taken from the optimized geometry at the same level.

It was surprising that the assignment of the E species was straightforward, whereas we expected it to be difficult because of the low barrier height. We searched first for $a$-type $R$ branch transitions in the scan, whose A-E splittings were expected to be small. Indeed, the E components were close to the A components with splittings from 0.2 to $0.5 \mathrm{GHz}$. The smallest splitting of $3.3 \mathrm{MHz}$ was found for the $6_{15} \leftarrow 5_{14}$ transition at $19.523 \mathrm{GHz}$.

Afterwards, $b$-type $R$ branch, $Q$ branch, and $P$ branch E species transitions with much larger A-E splittings from 2 to $2.5 \mathrm{GHz}$, from 1 to $4 \mathrm{GHz}$, and from 1 to $5 \mathrm{GHz}$, respectively, were also assigned. Finally, we identified $c$-type $Q$ branch and $P$ branch lines with splittings from 1.5 to $3.5 \mathrm{GHz}$ and 2 to $3 \mathrm{GHz}$, respectively. A global fit with $52 \mathrm{~A}$ and $40 \mathrm{E}$ species transitions was performed using the program XIAM to a rms deviation of $20.7 \mathrm{kHz}$, which is much larger than the experimental accuracy of $2 \mathrm{kHz}$. The fitted parameters are given as Fit A/E in Tab. 2. A list of all measured lines is available in Tab. S-5.

As an alternative, the same data set was fitted using the BELGI- $\mathrm{C}_{1}$ code. The starting values of the rotational constants $A, B$, and $C$ were derived by a transformation of the values obtained from Fit A/E in Tab. 2 into the rho axis system. The initial values of the internal rotation parameters $V_{3}, \rho$, and $F$ were taken directly from Fit A/E. The off-diagonal element $D_{a b}$ (multiplying the off-diagonal $\mathbf{P}_{a} \mathbf{P}_{b}+\mathbf{P}_{b} \mathbf{P}_{a}$ term) of the moment of inertia tensor was estimated from quantum chemical calculations. At first, we floated only the rotational constants $A, B$, and $C$ and fixed $V_{3}, \rho, F$, and $D_{a b}$ to the initial values. A reasonable rms deviation was obtained readily. Subsequently $V_{3}, \rho, F, D_{a b}$, and $D_{b c}$ (multiplying the off-diagonal $\mathbf{P}_{b} \mathbf{P}_{c}+\mathbf{P}_{c} \mathbf{P}_{b}$ term) were floated. We also took the centrifugal distortion constants 
Table 2. Molecular parameters in the principal axis system obtained using the XIAMcode (Fit A and Fit A/E) and the BELGI-C C $_{1}$ code (Fit BELGI). For the BELGI-C ${ }_{1}$ code, the molecular parameters in the rho axis system have been transformed into the principal axis system. Details on the conversion are given in Ref. 24. The calculated values were obtained at the MP2/6-311++G(d,p) level of theory.

\begin{tabular}{llllll}
\hline Par. & Unit & Fit A & Fit A/E & Fit BELGI & calc. \\
\hline$A$ & $\mathrm{GHz}$ & $8.45793267(91)$ & $8.10192(64)$ & $8.095373(67)$ & 8.0269 \\
$B$ & $\mathrm{GHz}$ & $1.68513289(15)$ & $1.6826992(47)$ & $1.6828322(52)$ & 1.6892 \\
$C$ & $\mathrm{GHz}$ & $1.46707430(13)$ & $1.4670091(12)$ & $1.46700749(61)$ & 1.4718 \\
$\Delta_{J}$ & $\mathrm{kHz}$ & $0.8290(19)$ & $0.819(15)$ & $1.0049(26)$ & 0.106 \\
$\Delta_{J K}$ & $\mathrm{kHz}$ & $-4.262(11)$ & $-4.562(73)$ & - & 1.809 \\
$\Delta_{K}$ & $\mathrm{kHz}$ & $56.49(21)$ & $48.5(21)$ & - & 37.045 \\
$d_{1}$ & $\mathrm{kHz}$ & $-0.20590(59)$ & $-0.2029(47)$ & - & 0.247 \\
$d_{2}$ & $\mathrm{kHz}$ & $-0.0214(16)$ & - & - & 4.491 \\
$V_{3}$ & $\mathrm{~cm}-1$ & - & $9.4552(94)$ & $9.099(68)$ & 7.725 \\
$\rho$ & - & - & $0.046435978^{a}$ & $0.04734(11)$ & 0.0479 \\
$\measuredangle(\mathrm{i}, a)$ & $\circ$ & - & $22.5843(15)$ & $22.54908(67)$ & 22.32 \\
$\measuredangle(\mathrm{i}, b)$ & $\circ$ & - & $67.8091(16)$ & $67.84554(64)$ & 68.07 \\
$\measuredangle(\mathrm{i}, c)$ & $\circ$ & - & $86.0123(7)$ & $86.00870(22)$ & 86.02 \\
$D_{p i 2 J}$ & $\mathrm{kHz}$ & - & $1.58(48)$ & - & - \\
$D_{p i 2 K}$ & $\mathrm{kHz}$ & - & $-769(93)$ & - & - \\
$D_{p i 2-}$ & $\mathrm{kHz}$ & - & $-17.56(65)$ & - & - \\
$F_{0}$ & $\mathrm{GHz}$ & - & $161.69(29)$ & $158.173(17)$ & 159.83 \\
$I_{\alpha}$ & $\mathrm{uA}{ }^{2}$ & - & $3.1256(55)^{a}$ & $3.19509(31)^{a}$ & 3.1619 \\
$\mathrm{~N}_{A} / \mathrm{N}_{E}{ }^{b}$ & - & $52 / 0$ & $52 / 40$ & $52 / 40$ & - \\
$\sigma$ & $\mathrm{kHz}$ & 2.1 & 20.7 & 1.5 & - \\
\hline
\end{tabular}

Standard error in parentheses in the units of the last digit.

Watson's S reduction and the $\mathrm{I}^{r}$ representation were used.

a Derived from $F_{0}$.

${ }^{\mathrm{b}}$ Number of fitted A and E species lines, respectively.

and higher order parameters into account. It should be noted that only two of the three off-diagonal elements $D_{a b}, D_{b c}$, and $D_{a c}$ (multiplying the off-diagonal $\mathbf{P}_{a} \mathbf{P}_{c}$ $+\mathbf{P}_{c} \mathbf{P}_{a}$ term) can be fitted because of a high correlation between those terms. In this case, we floated $D_{a b}$ and $D_{b c}$ since a lower rms deviation was achieved. With 18 fitted parameters, the overall $\mathrm{rms}$ deviation is $1.5 \mathrm{kHz}$, which is within the experimental accuracy and is reduced by a factor of 13 compared to Fit A/E. The BELGI- $\mathrm{C}_{1}$ parameters in the rho axis system are presented in Tab. 3. Parameters, which can be transformed into the principal axis system are given as Fit BELGI in Tab. 2.

\subsection{Discussion}

Using the programs XIAM and BELGI- $\mathrm{C}_{1}, 92$ torsional components of 3-pentyn-1-ol were fitted to a rms deviation of 20.7 and $1.5 \mathrm{kHz}$, respectively. As mentioned in section 2.2 , both programs have their individual advantages and disadvantages. BELGI-C $_{1}$ takes the interaction between different torsional states into account and includes more higher order terms. Therefore, the BELGI- $\mathrm{C}_{1}$ fit provides a much lower rms deviation and has higher predictive power, especially for the E species. The program XIAM on the other hand is well-suited for the assignment step, because it is fast, user-friendly, and yields parameters with physical meaning and small correlations.

The rotational constants $A, B, C$ deduced from the XIAM and BELGI- $\mathrm{C}_{1}$ fits are quite consistent and in good agreement with the values calculated at the MP2/6$311++\mathrm{G}(\mathrm{d}, \mathrm{p})$ level of theory. Calculations at different levels of theory yield quite good $B$ and $C$ rotational constants, but the calculated $A$ rotational constant is much worse. Fit A in Tab. 2 indicates that for the A species, a semi-rigid rotor fit with centrifugal distortion correction is quite satisfactory even for a molecule 
Table 3. Molecular parameters in the rho axis system obtained by a global fit using the BELGI- $\mathrm{C}_{1}$ code.

\begin{tabular}{|c|c|c|c|}
\hline Par. ${ }^{a}$ & Unit & Value $^{b}$ & Operator $^{c}$ \\
\hline$A$ & $\mathrm{GHz}$ & $8.04828(67)$ & $\mathbf{P}_{a}^{2}$ \\
\hline$B$ & $\mathrm{GHz}$ & $1.72410940(50)$ & $\mathbf{P}_{b}^{2}$ \\
\hline$C$ & $\mathrm{GHz}$ & $1.47281843(52)$ & $\mathbf{P}_{c}^{2}$ \\
\hline$D_{a b}$ & $\mathrm{GHz}$ & $-0.547725(12)$ & $\left\{\mathbf{P}_{a}, \mathbf{P}_{b}\right\}$ \\
\hline$D_{b c}$ & $\mathrm{GHz}$ & $0.0350587(11)$ & $\left\{\mathbf{P}_{b}, \mathbf{P}_{c}\right\}$ \\
\hline$d_{a b}$ & $\mathrm{kHz}$ & $-1134(13)$ & $\left\{\mathbf{P}_{a}, \mathbf{P}_{b}\right\}(1-\cos (3 \alpha))$ \\
\hline$d_{a b J}$ & $\mathrm{kHz}$ & $1.885(22)$ & $\mathbf{P}^{2}\left\{\mathbf{P}_{a}, \mathbf{P}_{b}\right\}(1-\cos (3 \alpha))$ \\
\hline$V_{3}$ & $\mathrm{~cm}^{-1}$ & $9.099(68)$ & $\frac{1}{2}(1-\cos (3 \alpha))$ \\
\hline$\rho$ & - & $0.04734(11)$ & $\mathbf{P}_{a} \mathbf{p}_{\alpha}$ \\
\hline$\Delta_{J}$ & $\mathrm{kHz}$ & $1.0049(26)$ & $-\mathbf{P}^{4}$ \\
\hline$\Delta_{K}$ & $\mathrm{kHz}$ & $52.69(17)$ & $-\mathbf{P}_{a}^{4}$ \\
\hline$\Delta_{J K}$ & $\mathrm{kHz}$ & $-5.9109(96)$ & $-\mathbf{P}^{a} \mathbf{P}_{a}^{2}$ \\
\hline$\delta_{j}$ & $\mathrm{kHz}$ & $0.28475(72)$ & $-2 \mathbf{P}^{2}\left(\mathbf{P}_{b}^{2}-\mathbf{P}_{c}^{2}\right)$ \\
\hline$\delta_{k}$ & $\mathrm{kHz}$ & $3.54(22)$ & $-\left\{\mathbf{P}_{a}^{2},\left(\mathbf{P}_{b}^{2}-\mathbf{P}_{c}^{2}\right)\right\}$ \\
\hline$k_{1}$ & $\mathrm{kHz}$ & $513(21)$ & $\mathbf{P}_{a}^{2} \mathbf{P}_{a} \mathbf{p}_{\alpha}$ \\
\hline$k_{2}$ & $\mathrm{kHz}$ & $-3680(460)$ & $\mathbf{P}_{a}^{2} \mathbf{p}_{\alpha}^{2}$ \\
\hline$c_{4}$ & $\mathrm{kHz}$ & $4.29(32)$ & $\left(\mathbf{P}_{b}^{2}-\mathbf{P}_{c}^{2}\right) \mathbf{P}_{a} \mathbf{p}_{\alpha}$ \\
\hline$F$ & $\mathrm{GHz}$ & $165.65(45)$ & $\mathbf{p}_{\alpha}^{2}$ \\
\hline$\sigma$ & $\mathrm{kHz}$ & 1.5 & - \\
\hline $\mathrm{N}_{A} / \mathrm{N}_{E}$ & - & $52 / 40^{d}$ & - \\
\hline
\end{tabular}

a All constants refer to a rho axis system, therefore the inertia tensor is not diagonal and the constants cannot be directly compared to those of a principal axis system. $\mathbf{P}_{a}, \mathbf{P}_{b}, \mathbf{P}_{c}$ are the components of the overall rotation angular momentum, $\mathbf{p}_{\alpha}$ is the angular momentum of the internal rotor rotating about the internal rotor axis by an angle $\alpha$. $\{\mathbf{A}, \mathbf{B}\}$ is the anticommutator $\mathbf{A B}+\mathbf{B A}$.

$\mathrm{b}$ Values of the parameters from the present fit. Statistical uncertainties are shown as one standard uncertainty in the last digit.

c The product of the parameter and operator from a given row yields the term actually used in the vibration-rotationtorsion Hamiltonian, except for $F, \rho$, and $A$, which occur in the Hamiltonian in the form $F\left(\mathbf{p}_{\alpha}-\rho \mathbf{P}_{a}\right)^{2}+A \mathbf{P}_{a}^{2}$.

d Number of fitted $\mathrm{A}$ and $\mathrm{E}$ species lines, respectively.

with a barrier as low as $10 \mathrm{~cm}^{-1}$ like 3-pentyn-1-ol. The rms deviation of $2.1 \mathrm{kHz}$ is essentially the measurement accuracy. Of course the rotational constants from this fit do not represent the molecular structure, as can be seen by comparison of the quite different $A$ rotational constants from Fit A and Fit A/E in Tab. 2.

The barrier to internal rotation of the propynyl methyl group was fitted by the program XIAM to $9.4552(94) \mathrm{cm}^{-1}$, which is close to the barrier of $9.099(68) \mathrm{cm}^{-1}$ given by BELGI- $\mathrm{C}_{1}$. The angles between the internal rotor axis and the principal axes as well as the internal rotation constant $F_{0}$ obtained from the XIAM fits, the BELGI fit, and ab initio are in good agreement. The six-fold contribution to the barrier is assumed to be negligible. However, with only ground state torsional transitions, it is impossible to test the validity of this assumption, as $V_{6}$ cannot be determined. On the other hand, we found that, contrary to the situation found for m-fluorotoluene [2] or trans-methyl nitrite [3], the fits are quite good. Therefore, we have not been troubled with ambiguities in the determination of the barrier. Unfortunately, a correlation between the $A$ rotational constant and $I_{\alpha}$ is responsible for the relatively large uncertainties in these parameters.

The rms deviation of $20.7 \mathrm{kHz}$ of the XIAM fit were approximately 10 times the measurement accuracy, which is surprisingly good considering the very low propynyl methyl barrier of 3-pentyn-1-ol. Larger deviations have been found in other internal rotation problems with higher barriers treated by the program XIAM, i.a. ethyl acetate $\left(101.606(23) \mathrm{cm}^{-1}, 85.3 \mathrm{kHz}\right)$ [24], allyl acetate $\left(98.093(12) \mathrm{cm}^{-1}\right.$, $54.0 \mathrm{kHz})[22]$ and vinyl acetate $\left(151.492(34) \mathrm{cm}^{-1}, 92.3 \mathrm{kHz}\right)$ [25]. XIAM appears 
to work quite well in this case, and we conclude that the deviation that is much larger than the measurement accuracy could be due to the limited amount of fit parameters rather than to an inadequacy of this program for low barriers.

In comparison to the values found for other molecules containing the propynyl methyl group mentioned in the introduction $\left(\mathbf{R}=\mathrm{CD}_{3}, \mathrm{SiH}_{3}, \mathrm{CH}_{2} \mathrm{Cl}, \mathrm{CH}_{2} \mathrm{OH}\right.$, $\mathrm{COF}, \mathrm{COOH})$, the barrier in 3-pentyn-1-ol is closest to that of 1-chloro-2-butyne $\left(10.05(9) \mathrm{cm}^{-1}\right)$ [11]. Comparing to that of 2-butynol [10], the barrier is slightly higher. Since still few examples for the internal rotation of the propynyl methyl group are available, it is not possible to give a general statement on the influence of different $\mathbf{R}$ substitutions on the barrier height.

In cases of molecules with a higher $V_{3}$ potential barrier (say $>50 \mathrm{~cm}^{-1}$ ), the barrier to internal rotation cannot often be reliably calculated using quantum chemical calculations at the levels of theory we used [26, 27]. In the contrary, the barriers for 3-pentyn-1-ol calculated at different levels of theory are relatively consistent and only vary in a small range of about $7 \mathrm{~cm}^{-1}$ (see Tab. S-3).

The structure of the five conformers found on the PES of 3-pentyn-1-ol is essentially the same as those illustrated in Fig. 1 in the investigation on 3-butyn-1-ol by Szalanski and Ford [12], where the propynyl methyl group in 3-pentyn-1-ol is substituted by a proton. There, only one conformer was observed (shown in Fig. 2 of Ref. 12), which has a hydrogen bound gauche form where the $\mathrm{OH}$ group is bound back to the triple bond. This is also the heavy atom skeleton of conformer $\mathbf{I}$ of 3-pentyn-1-ol.

\section{Acknowledgment}

We thank the Land Nordrhein-Westfalen for funds and the IT Center of the RWTH Aachen University for free computer time. K. E. thanks the Université Paris-Est Créteil for travel funding, which enabled him to work at Paris for two months. R. K. thanks the Graduate fund of the RWTH Aachen University for a Ph.D. fellowship.

\section{References}

[1] V.V. Ilyushin, E.A. Alekseev, S.F. Dyubko, I. Kleiner and J.T. Hougen, J. Mol. Spectrosc. 227, 115 (2004).

[2] H.D. Rudolph and A. Trinkaus, Z. Naturforsch. 23, 68 (1968).

[3] P.H. Turner, M.J. Corkill and A.P. Cox, J. Phys. Chem. 83, 1473 (1979).

[4] R.M. Pitzer, Acc. Chem. Res. 16, 207 (1983).

[5] P.R. Bunker and H.C. Longuet-Higgins, Proc. Roy. Soc. A 280, 340 (1964).

[6] J. Nakagawa, M. Hayashi, Y. Endo, S. Saito and E. Hirota, J. Chem. Phys. 80, 5922 (1984).

[7] J. Nakagawa, K. Yamada, M. Bestera and G. Winnerwisser, J. Mol. Spectrosc. 110, 74 (1985).

[8] K.D. Hensel and M.C.L. Gerry, J. Chem. Soc. Faraday Trans. 90, 3023 (1994).

[9] V. Ilyushin, R. Rizzato, L. Evangelisti, G. Feng, A. Maris, S. Melandri and W. Caminati, J. Mol. Spectrosc. 267, 186 (2011).

[10] R. Subramanian, S.E. Novick and R.K. Bohn, J. Mol. Spectrosc. 222, 57 (2003).

[11] V.M. Stolwijk and B.P. van Eijck, J. Mol. Spectrosc. 124, 92 (1987).

[12] L.B. Szalansko and R.G. Ford, J. Mol. Spectrosc. 54, 148 (1975).

[13] Gaussian 09, Revision A.1, M.J. Frisch, G.W. Trucks, H.B. Schlegel, G.E. Scuseria, M.A. Robb, G.S. J. R. Cheeseman, V. Barone, B. Mennucci, G.A. Petersson, H. Nakatsuji, M. Caricato, X. Li, H.P. Hratchian, A.F. Izmaylov, J. Bloino, G. Zheng, J.L. Sonnenberg, M. Hada, M. Ehara, K. Toyota, R. Fukuda, J. Hasegawa, M. Ishida, T. Nakajima, Y. Honda, O. Kitao, H. Nakai, T. Vreven, J.A. Montgomery, Jr., J.E. Peralta, F. Ogliaro, M. Bearpark, J.J. Heyd, E. Brothers, K.N. Kudin, V.N. Staroverov, R. Kobayashi, J. Normand, K. Raghavachari, A. Rendell, J.C. Burant, S.S. Iyengar, J. Tomasi, M. Cossi, N. Rega, J.M. Millam, M. Klene, J.E. Knox, J.B. Cross, V. Bakken, C. Adamo, J. Jaramillo, R. Gomperts, R.E. Stratmann, O. 
Yazyev, A.J. Austin, R. Cammi, C. Pomelli, J.W. Ochterski, R.L. Martin, K. Morokuma, V.G. Zakrzewski, G.A. Voth, P. Salvador, J.J. Dannenberg, S. Dapprich, A.D. Daniels, Farkas, J.B. Foresman, J.V. Ortiz, J. Cioslowski and D.J. Fox, Gaussian, Inc., Wallingford CT (2009).

[14] C.C. Lin and J.D. Swalen, Rev. Mod. Phys. 31, 841 (1959).

[15] H. Hartwig and H. Dreizler, Z. Naturforsch. 51, 923 (1996).

[16] I. Kleiner and J.T. Hougen, J. Chem. Phys. 119, 5505 (2003).

[17] Z. Kisiel, http://www.ifpan.edu.pl/ kisiel/prospe, Programs for ROtational SPEctroscopy.

[18] E. Herbst, J.K. Messer, F.C. DeLucia and P. Helminger, J. Mol. Spectrosc. 108, 42 (1984).

[19] I. Kleiner, J. Mol. Spectrosc. 260, 1 (2010).

[20] L.W. Sutikdja, D. Jelisavac, W. Stahl and I. Kleiner, Mol. Phys. 110, 2883 (2012).

[21] L. Tulimat, H. Mouhib, I. Kleiner and W. Stahl, J. Mol. Spectrosc. 312, 46 (2015).

[22] H.V.L. Nguyen, H. Mouhib, W. Stahl and I. Kleiner, Mol. Phys. 108, 763 (2011).

[23] J.-U. Grabow, W. Stahl and H. Dreizler, Rev. Sci. Instrum. 67, 4072 (1996).

[24] D. Jelisavac, D.C. Córtes Gómez, H.V.L. Nguyen, L.W. Sutikdja, W. Stahl and I. Kleiner, J. Mol. Spectrosc. 257, 111 (2009).

[25] H.V.L. Nguyen, A. Jabri, V. Van and W. Stahl, J. Chem. Phys. 118, 12130 (2014).

[26] A. Jabri, V. Van, H.V.L. Nguyen, W. Stahl and I. Kleiner, ChemPhysChem, DOI: 10.1002/cphc.201600265 (2016).

[27] V. Van, W. Stahl and H.V.L. Nguyen, Phys. Chem. Chem. Phys. 17, 32111 (2015). 